UDC 004.491:005.21

Preliminary Communication

\title{
The Elaboration of Strategic Decisions in the Socio-Economic Systems
}

\author{
Anna Alekseevna Khanova \\ Astrakhan State Technical University \\ Astrakhan, Russian Federation
}

Oleg Miroslavovich Protalinskiy Astrakhan State Technical University

Astrakhan, Russian Federation

Kristina Igorevna Averianova

Astrakhan State Technical University

Astrakhan, Russian Federation akhanova@mail.ru

protalinskiy@gmail.com

averjanovacristina@yandex.ru

\begin{abstract}
The article deals with socio-economic strategic management, which implemented on the basis of Balanced Scorecard, multidimensional modeling and its set-theoretic representation. The main idea of the article is using of modern information technology to assist in decision-making. Much attention is given to formalization of SCIPEOmodeling and integration of its sub-model. The process of developing of management decisions is considered. The integration of these tools will improve the management of the system in a situation of total or partial indeterminacy.
\end{abstract}

Keywords: socio-economic system, SCIPEO-modeling, integrated multidimensional domain model.

\section{Introduction}

Socio-economic systems (company or organization) must constantly adapt to changing market conditions, ahead of their competitors in quality, speed and flexibility of the products (services) to achieve success in a complex and dynamic environment. This is impossible without prompt obtaining information by guidance of the activities of the socio-economic system (SES) for timely decision-making before it will be reflected on financial results [1]. At the same time, even the prompt action of the enterprise must be coordinated and aimed at the achievement of certain long-term goals expressed in indicators, which are often uncoordinated. They do not give a complete picture and do not allow judging the success of the implementation of business strategy. The improvementon control mechanisms in the SES becomes relevant. It includes the ability to evaluate the effectiveness of achieving strategic 
goals based on a set of indicators and the possibility of formation management decisions, considering the risk of failure to reach such goals.

\section{The system interconnection of strategic management in socio- economic systems}

The SES characterizes a set of interrelated control, technological and informational factors, the integration of economies and societies, representing the interdependent functioning of the social product or service. The management of this integration is based on the theory of organizational systems [2]. The complexity and interaction of the individual components of the SES and the production processes (services) $\left(\mathrm{PP}_{1}\right.$, $\mathrm{PP}_{2}, \ldots \mathrm{PP}_{\mathrm{n}}$ ) make it necessary in strategic management indicators, which used not only in profitable products, but also in the origins of the financial value, i.e. in the sphere of employees, customers, the structural and procedural organization of the SES (Fig. 1a).

Consider the approach to the management of SES, based on the Balanced Scorecard (BSC). Director chooses the strategy of development of SES. BSC is formed into a plurality of disparate indicators of the SES activities in accordance with a predetermined strategy, and is closely related to risk assessment. The BSC creates a strategic map showing the essential indicators from the list of indicators of SES and actual data (Fig. 1b). Simultaneously the risk register is formed. Director forms the managerial decision (MD), aimed at improving essential indicators (Fig. 1). The concept is formulated in $[3,4]$ and includes the principles of the system sufficient for a wide range of management problem.

\section{The multidimensional integrated modeling of subject domain}

Complex socioeconomic systems require consolidation and visualization of large volumes of diverse data with software and hardware systems. We propose to use situational-cognitive-imitation-process-expert-ontological (SCIPEO) modeling as a scientific and methodological basis for complex integration and convergence of simulation systems. It is the development of the concept of situational-imitationexpert (SIE) modeling, proposed by Filippovich A.U. [5-6]. The underlying principle of SCIPEO-modeling is the representation of cogitative activity of the decision-maker (DM) by means of six types of models representation of subject areas:

- the ontological model $(\mathrm{OM})$ is a structuring tool for the description and analysis of the problem situation in the SES [7];

- the process model (PM) is used to analyze the internal environment of the system and describe the sequence of system changes [8];

- the imitating model (IM) details the decision, distributes authority and resources through the application of logistics management methods and the variety of techniques for the analysis of fixed assets, the quality of products and services, etc. [9]; 


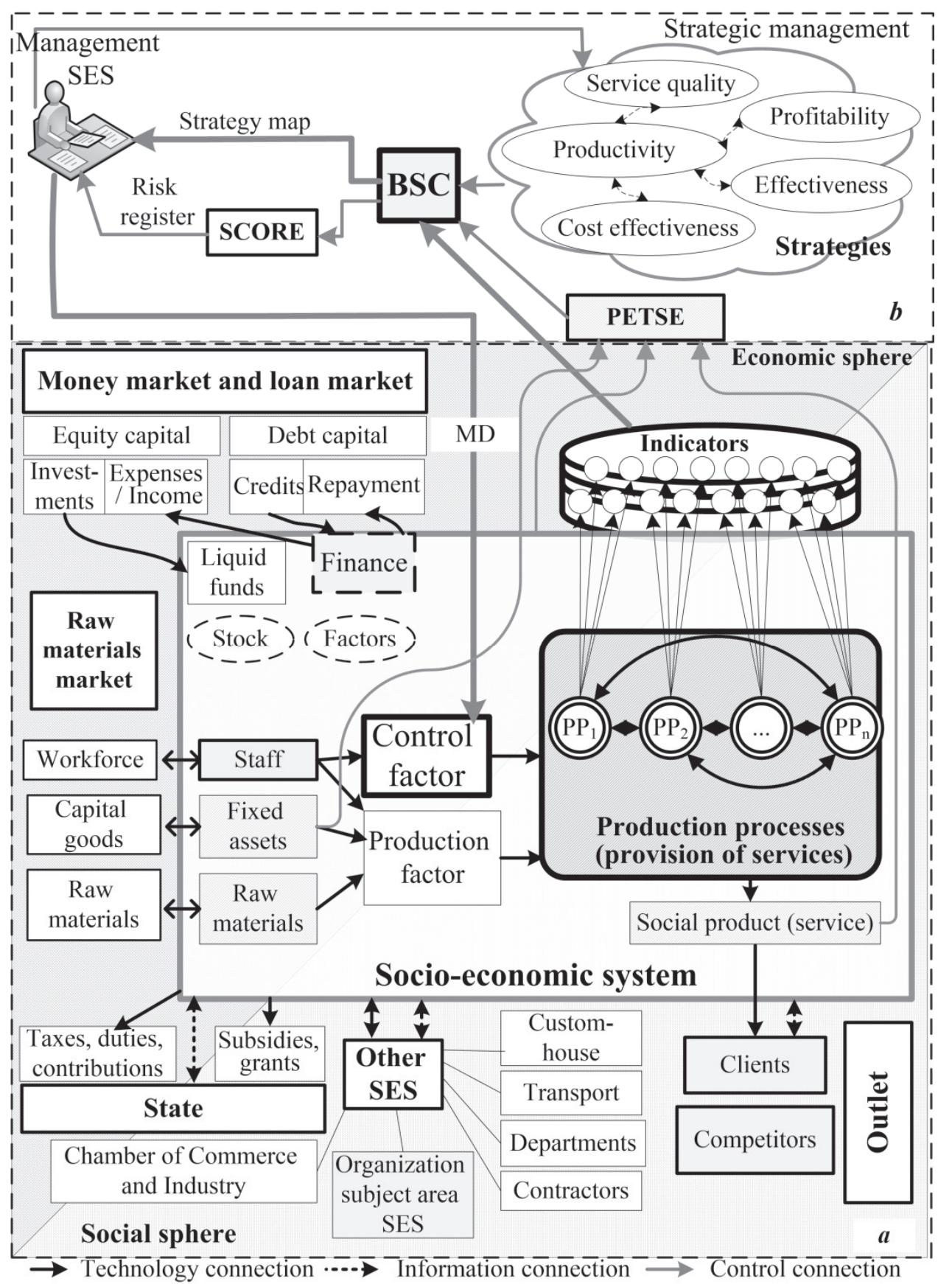

Figure. 1.Systemic interconnections of strategic management (b)processes in the SES (a) 
- the expert model (EM) is a neural network trained for the basis of expert data. It is used to define a set of goals in the BSC and imitate human reasoning processes;

- the cognitive model (CM) allows you to set mutual influence of indicators based on cognitive maps. It is used to assess configuration alternatives of the SES;

- the situational model (SM) is designed to generate management decisions (MD) [10].

\section{The formalization of SCIPEO-models}

The integrated SCIPIO-modeling assumes a single set of elements (concepts) used in multidimensionalrepresentation of subject domain. Many elements of SCIPEOdomain model are formed by combining the sets of elements of SM, CM, IM, PM, EM and OM (Figure 2.)

$$
G^{M L_{S C I P E O}}=G^{M L_{S}} \cup G^{M L_{C}} \cup G^{M L_{I}} \cup G^{M L_{P}} \cup G^{M L_{E}} \cup G^{M L_{O}},
$$

where $\boldsymbol{G}^{\boldsymbol{M} \boldsymbol{L}_{\boldsymbol{S}}}$ a plurality elements of the SM, $\boldsymbol{G}^{\boldsymbol{M} \boldsymbol{L}_{\boldsymbol{C}}}$ - a plurality elements of the CM,

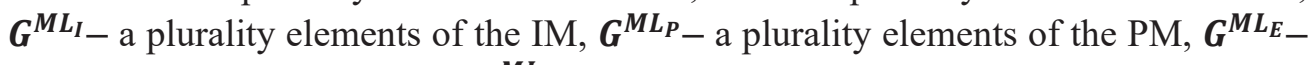
a plurality elements of theEM, $\boldsymbol{G}^{\boldsymbol{M} \boldsymbol{L}_{\boldsymbol{O}}}$ - a plurality elements of the OM.

All models have several elements and concepts that are unique to them and are not used in other models. Combinationsthese elements are quite simple:

$$
\begin{aligned}
& G^{M L_{S C I P E O}}=\left(G_{*}^{M L_{S}} \cup G_{*}^{M L_{C}} \cup G_{*}^{M L_{I}} \cup G_{*}^{M L_{P}} \cup G_{*}^{M L_{E}} \cup G_{*}^{M L_{O}}\right) \cup \\
& \left(G_{-*}^{M L_{S}} \cup G_{-*}^{M L_{C}} \cup G_{-*}^{M L_{I}} \cup G_{-*}^{M L_{P}} \cup G_{-*}^{M L_{E}} \cup G_{-*}^{M L_{O}}\right), \\
& \left(G_{*}^{M L_{S}} \cap G_{*}^{M L_{C}}\right)=\left(G_{*}^{M L_{S}} \cap G_{*}^{M L_{I}}\right)=\left(G_{*}^{M L_{S}} \cap G_{*}^{M L_{P}}\right)=\left(G_{*}^{M L_{S}} \cap G_{*}^{M L_{E}}\right)= \\
& \left(G_{*}^{M L_{S}} \cap G_{*}^{M L_{O}}\right)=\left(G_{*}^{M L_{C}} \cap G_{*}^{M L_{I}}\right)=\left(G_{*}^{M L_{C}} \cap G_{*}^{M L_{P}}\right)=\left(G_{*}^{M L_{C}} \cap G_{*}^{M L_{E}}\right)= \\
& \left(G_{*}^{M L_{C}} \cap G_{*}^{M L_{O}}\right)=\left(G_{*}^{M L_{I}} \cap G_{*}^{M L_{P}}\right)=\left(G_{*}^{M L_{I}} \cap G_{*}^{M L_{E}}\right)=\left(G_{*}^{M L_{I}} \cap G_{*}^{M L_{O}}\right) \\
& =\left(G_{*}^{M L_{P}} \cap G_{*}^{M L_{E}}\right)=\left(G_{*}^{M L_{P}} \cap G_{*}^{M L_{O}}\right)=\left(G_{*}^{M L_{E}} \cap G_{*}^{M L_{O}}\right)=\varnothing ; \\
& \left(G_{-*}^{M L_{S}} \cap G_{-*}^{M L_{C}}\right) \neq \varnothing ;\left(G_{-*}^{M L_{S}} \cap G_{-*}^{M L_{I}}\right) \neq \varnothing ;\left(G_{-*}^{M L_{S}} \cap G_{-*}^{M L_{P}}\right) \neq \emptyset ; \\
& \left(G_{-*}^{M L_{S}} \cap G_{-*}^{M L_{E}}\right) \neq \emptyset ;\left(G_{-*}^{M L_{S}} \cap G_{-*}^{M L_{O}}\right) \neq \emptyset ;\left(G_{-*}^{M L_{C}} \cap G_{-*}^{M L_{I}}\right) \neq \varnothing ; \\
& \left(G_{-*}^{M L_{C}} \cap G_{-*}^{M L_{P}}\right) \neq \varnothing ;\left(G_{-*}^{M L_{C}} \cap G_{-*}^{M L_{E}}\right) \neq \varnothing ;\left(G_{-*}^{M L_{C}} \cap G_{-*}^{M L_{O}}\right) \neq \varnothing ; \\
& \left(G_{-*}^{M L_{I}} \cap G_{-*}^{M L_{P}}\right) \neq \varnothing ;\left(G_{-*}^{M L_{I}} \cap G_{-*}^{M L_{E}}\right) \neq \varnothing ;\left(G_{-*}^{M L_{I}} \cap G_{-*}^{M L_{O}}\right) \neq \varnothing ; \\
& \left(G_{-*}^{M L_{P}} \cap G_{-*}^{M L_{E}}\right) \neq \varnothing ;\left(G_{-*}^{M L_{P}} \cap G_{-*}^{M L_{O}}\right) \neq \varnothing ;\left(G_{-*}^{M L_{E}} \cap G_{-*}^{M L_{O}}\right) \neq \varnothing \text {. }
\end{aligned}
$$

where $G_{*}^{M L_{S}}\left[G_{-*}^{M L_{S}}\right]$ - a variety of [non] unique elements of the SM, $G_{*}^{M L_{C}}\left[G_{-*}^{M L_{C}}\right]-$ a variety of [non] unique elements of the CM, $G_{*}^{M L_{I}}\left[G_{-*}^{M L_{I}}\right]-$ a variety of [non] unique elements of the IM, $G_{*}^{M L_{P}}\left[G_{-*}^{M L_{P}}\right]$ - a variety of [non] unique elements of the PM, $G_{*}^{M L_{E}}\left[G_{-*}^{M L_{E}}\right]$ - a variety of [non] unique elements of the EM, $G_{*}^{M L_{O}}\left[G_{-*}^{M L_{O}}\right]-$ a variety of [non] unique elements of the OM. However, there are elements which are used in many models. They need to develop new generalized elements (meta-elements) or use a different view [5-6]. 


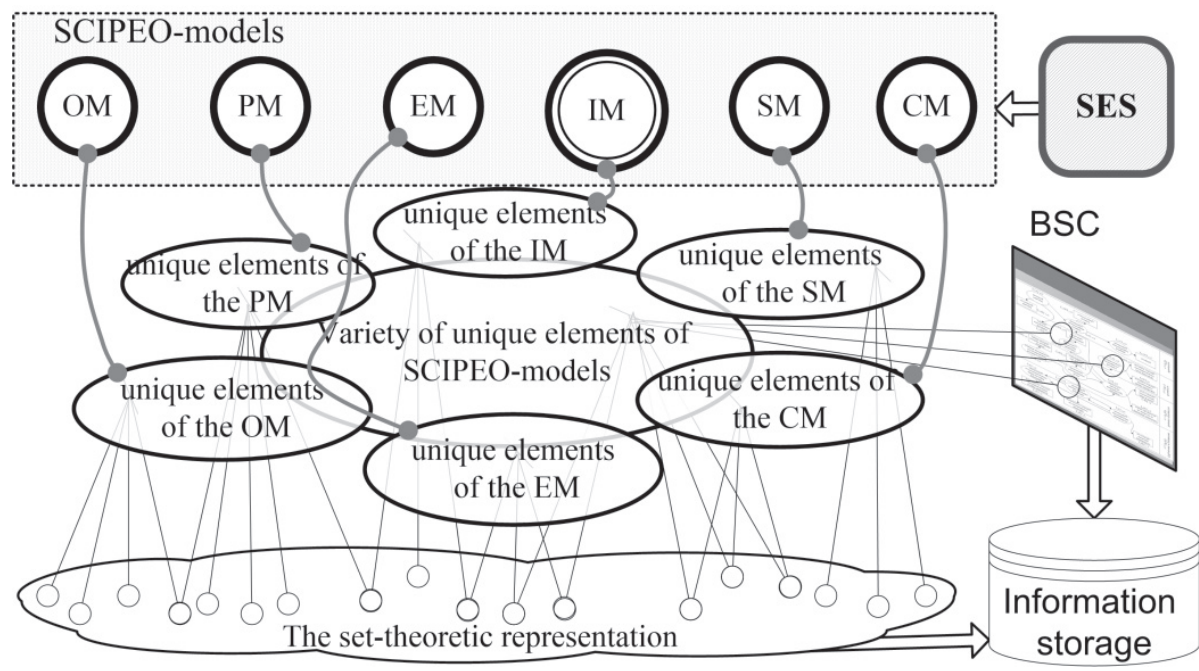

Figure. 2.The multidimensionalrepresentation of subject domain

Common elements must be duplicated (projected) in each aspect in a different view, or contained in one aspect. In the last case aspects should be able to refer to the corresponding element. We have described the information structure of the SCIPEO-models of the SES in the external environment, changes from the parameters of business processes by varying the influence of internal and external influences on the activities of SES or a separate PP.

Formal means of information modeling are used to create static and dynamic models of the system processes. Static process models are created based on the DFD (Data Flow Diagram), methods of SADT (Structured Analysis and Design Technique), ERD (Entity Relationship Diagrams). Dynamic models are based on different network methods, such as Petri nets, Colored Petri nets (CPN) and simulation languages: unified GPSS (General Purpose Simulating System) and visual SIMAN (Simulation Analysis). [11].

Distinctive features of the static models are high descriptive ability the possibility of functional-cost analysis (FCA), the use of the International Standard (IDEF0)]. Dynamic model allows considering dynamics of the processes functioning and using stochastic components of the model. This gives the possibility of a comprehensive analysis of the field of study. Modern software simulation tools often use object-oriented approach (high level modeling language SIMAN). Thus solution to the problem description and analysis of the SES activities is advantageously carried out by combining the methods of static and dynamic modeling, structural and object-oriented approaches. This combination of methods and approaches provides large adaptability for analysis and optimization SES processes and increase the descriptive and modeling possibility [11]. We used the set-theoretic approach formalized description multidimensionalenterprise models after methodologies IDEF0, IDEF3 and SIMAN, expanded representation ontological models in the IDEF5 and the description of CM, SM and EM. 
$\mathrm{OM}$ is presented in a two-level design: $M L_{O}=\left\langle M L_{o}^{B Y},\left\{M L_{o}^{H Y}\right\}, M B\right\rangle$, where $M L_{o}^{B Y}$ - the top-level ontology (IDEF0), $\left\{M L_{o}^{H Y}\right\}$ - a plurality of lower-level ontologies (IDEF5); $M B$ - the output.

The top-level of OM (Figure 3) in terms of IDEF0-model is a set of four sets [12]:ML $L_{o}^{B Y}=\left\langle I_{M L_{o}}, U_{M L_{o}}, O_{M L_{o}}, M_{M L_{o}}\right\rangle$, where $I_{M L_{o}}$ - the finite set of arcs (inputs); $U_{M L_{O}}$ - the finite set of arcs (control); $M_{M L_{O}}$ - the finite set of objects (mechanisms); $O_{M L_{O}}-$ the finite set of arcs (outputs).

$$
\left\{\begin{array}{c}
I_{M L_{o}}=\left\{X_{P}, M_{p}\right\}, \\
U_{M L_{o}}=\{D L, P s u, S t r\}, \\
M_{M L_{o}}=\{R S, D L, O P\}, \\
O_{M L_{o}}=\left\{S, X_{f}, M_{f}\right\}
\end{array}\right.
$$

Elements (3) are identified in terms of the generalized contextual diagram PP system (Fig. 3): $X_{P^{-}}$the purpose process (PP according to the plan), and $X_{f}-$ the result of the process (PP in fact); $Y$ - a set of methods (management decisions), aimed at improving efficiency; $R S$ - the realization based on intellectual resources and tools; $M_{p^{-}}$the interpretation of purpose of the process (the set of planned BSC indicators values), $M_{f}$ - the interpretation of the results of the process (the set of actual BSC indicator values); Str-a plurality of SES strategies; (6) $D L-$ a plurality of regulations and constraints on resources; $P s u$ - principles of strategic management; $O P$ - a plurality of SES processes; $S$ - a plurality of situations in SES.

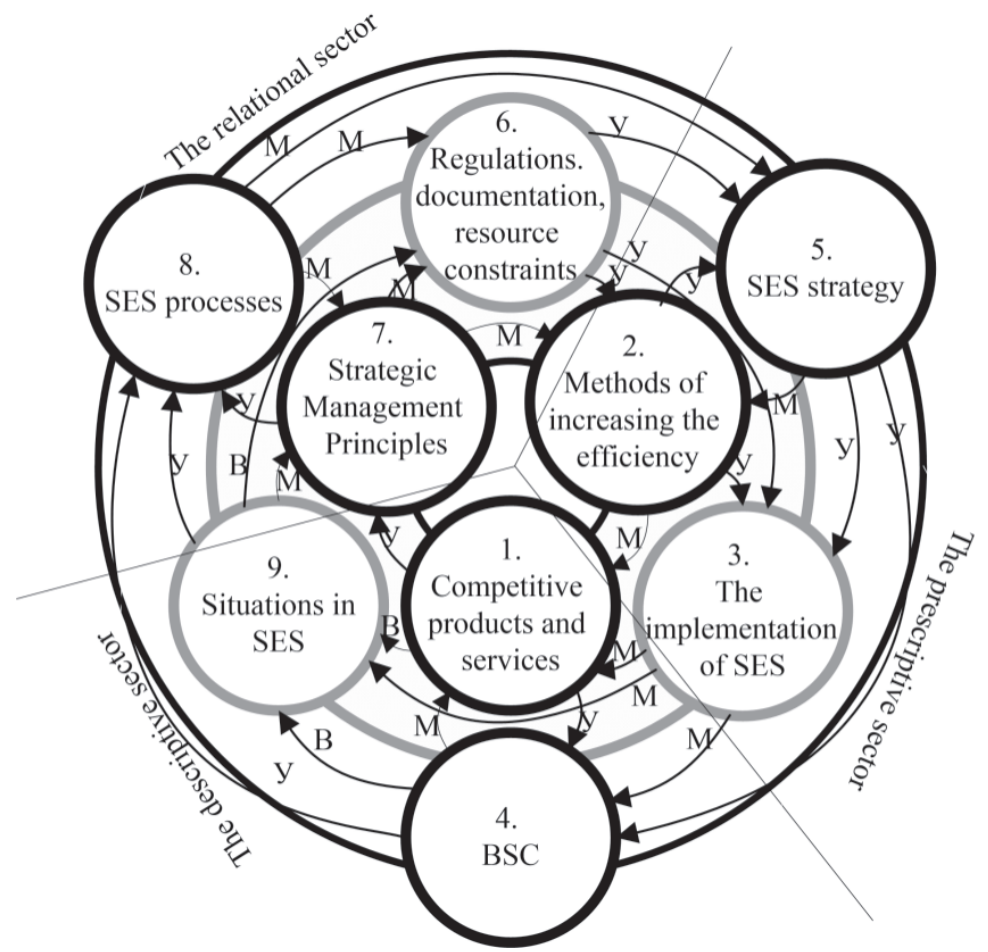

Figure. 3. The first level of the ontological model of SES 
IDEF0-models do not allow to set temporal and probability parameters, lack the capacity for forecasting and business planning [11]. Some of these disadvantages can be avoided by describing the PM using the methodology IDEF3. Then SES or the separate process is a model executing steps of sequence of operations excluding the temporal characteristics. Links are sources and receivers flows (data, information, materials, services) in the PM, implemented on the basis of the methodology IDEF3. Units of work determine the mechanism of the transformation of input flows to output flows [11]. IDEF3 PM formally defined as: $M L_{P}=$ $\langle O P, R P, L P$, Int $\rangle$, where $O P$ - a nonempty finite set of processes (work units), which are the vertices of the graph the $P M M L_{P}, O P=\left\{o p_{1}, o p_{2}, \ldots, o p_{n o p}\right\} ; R P-$ a finite non-empty set of resources (links), $R P=(R P I, R P O), \quad R P O=$ $\left\{r p o_{1}, r p o_{2}, \ldots r p o_{n r p o}\right\}, R P I=\left\{r p i_{1}, r p i_{2}, \ldots r p i_{n r p i}\right\}, R P I=h_{R P I}(O P, L P, R P O)$; $L P$ - a plurality of links, which are the arcs of the graph PM $M L_{P}$; Int- a plurality of intersections. The intersection allows describe the sequence of system changes and the sequence and logic execution stages, which allows establish the relationship between static and dynamic IM and transform IDEF3-model to SIMAN-model [13]. The imitating modeling system (IMS) Arena has special features for this purpose. The structure of SIMAN-model is a directed graph, whose vertices are the nodes connected by directed arcs.

SIMAN-model can be formally defined as: $M L_{I}=$ $\langle C r, D i s, O P, B T, \operatorname{Sep}, \mathrm{Dec}, A s, \tau\rangle$, where $\mathrm{Cr}$ - a non-empty finite set of sources, $C r=\left\{c r_{1}, c r_{2}, \ldots, c r_{n c r}\right\} ;$ Dis- a finite non-empty set of stocks, Dis = $\left\{d i s_{1}, d i s_{2}, \ldots, d i s_{n d i s}\right\} ; O P-$ a non-empty finite set of processes, $O P=$ $\left\{o p_{1}, o p_{2}, \ldots, o p_{n o p}\right\} ; B T-$ a finite set of group modules, $B T=\left\{b t_{1}, b t_{2}, \ldots, b t_{n b t}\right\}$; $S e p-$ a finite set of ungroup modules, $\operatorname{Sep}=\left\{\operatorname{sep}_{1}, \operatorname{sep}_{2}, \ldots, \operatorname{sep}_{n s e p}\right\} ; \mathrm{Dec}-\mathrm{a}$ finite nonempty set of conditions modules, $\operatorname{Dec}=\left\{\operatorname{dec}_{1}, \operatorname{dec}_{2}, \ldots, \operatorname{dec}_{n d e c}\right\} ; A s-\mathrm{a}$ set of parameters IM, $A s=\{S, M, Y\} ; \tau$ - time of SIMAN-model allow to fully describe the logic of any process, to explore time, cost and probability of the process parameters. Based on this we can plan, optimize and predict the activity of the company and the individual business processes.

The set-theoretic representation of EM is defined as: $M L_{E}=$ $\langle S t, M, X, E x p, N s t, w, T e, \eta, G e\rangle$, where Exp - experts; Nst - a number of neurons; $w$-a weight linking $i$-th input to $j$-th output; $T e-$ a number of training iterations; $\eta-\mathrm{a}$ rate constant of learning.

The set-theoretic representation of the $\mathrm{CM}$ is defined as: $M L_{C}=\langle S t, M, \omega\rangle$, where $M-\mathrm{BSC}$ indicators; $\omega$ - weighting coefficients between BSC indicators.

The set-theoretic representation of SM defined as: $M L_{S}=$ $\langle S, S t, X, M, Y, K a p o, \tau\rangle$, whereKapo- measures of efficiency.

This formalization has identified many unique elements of SCIPIO-model: $G_{-*}^{M L_{S C I P E O}}=\langle S r, X, M, Y, S, O P\rangle$. Most of the non-unique elements of SCIPEOmodel relates to the concepts of the Balanced Scorecard and to the SES (Fig. 2). The place each model defined in the development cycle management decisions in [14].

The development cycle scheme of management decisions (MD) on the basis of an integrated multidimensional domain model is shown in Figure 4. 


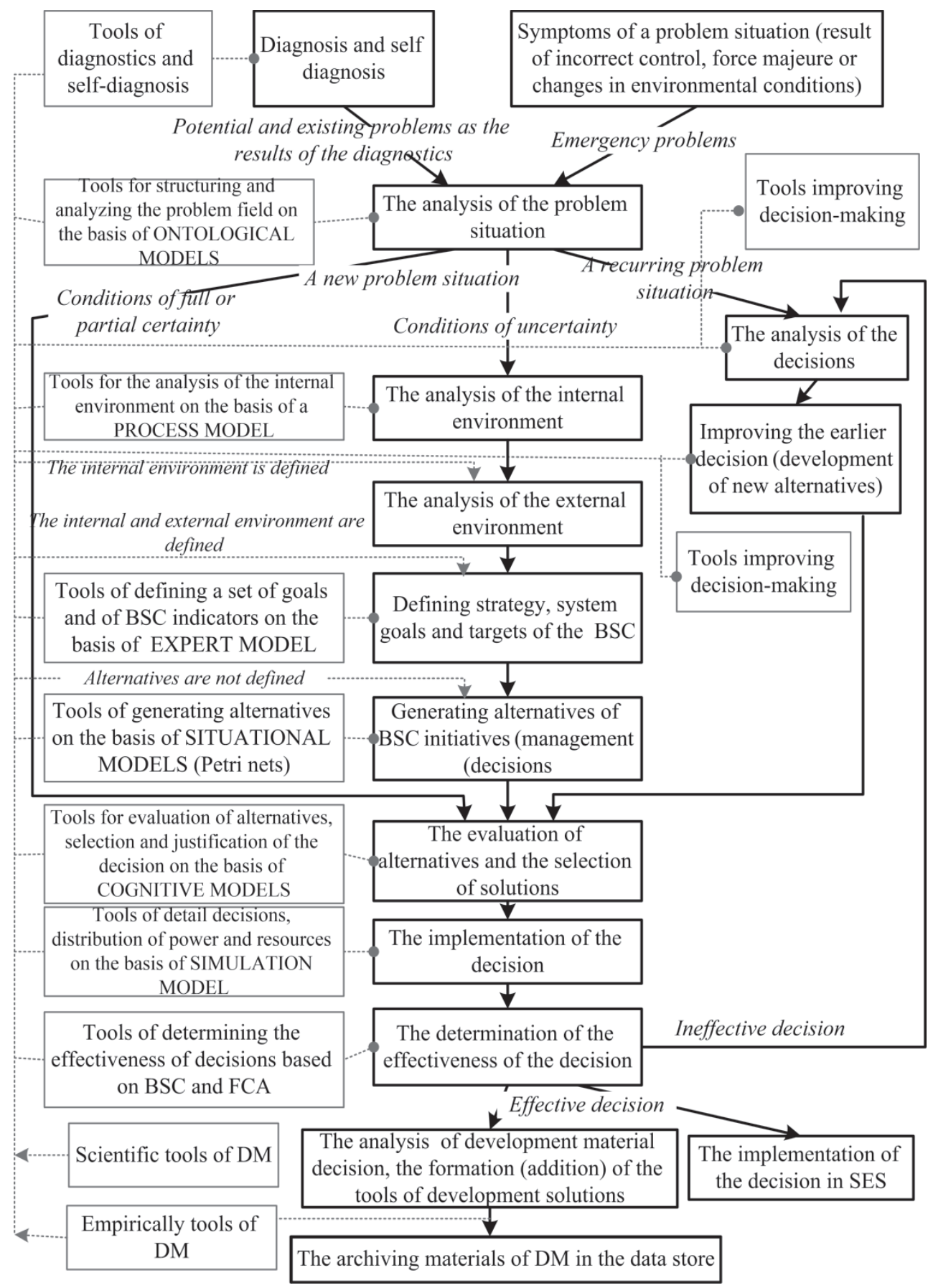

Figure. 4.The generalized cyclical nature scheme of the development process of MD with interconnection stages, conditions and tools in the form of set SCIPEO-models. 
If the result of the effectiveness of the MD implementation was low, then the MD needed to be modified or improved or developed again with SCIPEOmodels.Thus, the cyclical nature of the development of management decisions is shown.

The condition of stopping the development cycle of MD is the adoption and realization on the SCIPEO-models of management decision, providing the required effectiveness and the achievement of strategic objectives. If strategic objectives following the adoption of MD cannot be achieved in the course of a series of experiments on SCIPEO-models, objectives and strategy are exposed adjustment, and problematic situation is eliminated by other way.

Some problems (breakage of crane equipment) can be solved completely; other problems can be solved partially. Some of the problems cannot be resolved in general, but their sharpness can smooth out. These problems include the contradiction of strategic objectives of SES owners and management personnel or the contradiction between strategic objectives of the SES and competitors. In some cases, conflicts can be resolved by adjustment and harmonization purposes. But decisions considered significant if they are aimed at changing the specific situation [15]. The slight change of a situation suggests that relevant factors have been not taken into account or new factors have appeared as a result of constantly changing external conditions.

If problems in the activities of the enterprise are known, their priority is defined, strategic goals are set, criteria, alternatives of decision, outcomes of alternatives and their probabilities are formalized, the decision-maker must select a solution on the basis of personal preferences, ie. decidefor favor of the pure form, in full certainty. In this case some stage of the development of decisions can be omitted.

The situation is full of uncertainty is rare in the SES management practices. Typically, a plurality of strategic objectives should be identified with the development of the management decision, and alternatives and their outcomes should be formalized. In this case, the situation related to the class of cases of full or partial uncertainty [2].

Goals can be determined by circumstances or previously developed strategy. The problem with this case is a mismatch of strategic goals and the current status of SES, i.e. the conflict (the discrepancy existing and planned).

The criteria are a quantitative expression of BSC indicators. The decision rule is determined by identification of causal relationships between indicators of BSC in SES. Alternatives may be defined and bounded by available resources or exogenous factors.

The scheme (Figure 3) shows that the starting point for making decisions on the basis of integration and convergence of SCIPEO-model is the concept of "problem situation". The "situation" means that actions defined by context in the SES in which they are carried out. This concept is the basis of situational management theory, which studies the dependence of the management efficiency of the position in which their organization is applying. 


\section{Conclusion}

The SES is considered as a strategic management system based on the Balanced Scorecard. Multidimensionalintegrated view of subject domain structure based on the integration and convergence of ontological, process, simulation, expert, cognitive and situational models determined. The model of strategic management of socioeconomic systems is built. The formalization of the models in the set-theoretic representation carried out. Location of each model identified in the development cycle of management decisions.

\section{References}

[1] A. A. Khanova, A.S. Hortonen and L.V.Paramzina, "System interrelations of strategic management and modeling of social and economic systems based on the balanced system of parameters," Vestnik Astrakhanskogo Gosudarstvennogo Technicheskogo Universiteta. Series:Upravlenie, vyichislitelnaya tehnika i informatika, no.2, pp. 109-116, 2014.

[2] Yu. N. Lapygin and D.Yu. Lapygin, Management decisions: education guidance. Moscow, EKSMO, 2009.

[3] A.A. Khanova, O.M. Protalinski, A.F. Dorokhov and A.A. Bolshakov, "Socio-Economic Systems Strategic Management Concept Based on Simulation," World Applied Sciences J. Information Technologies in Modern Industry, Education \& Society, no. 24, pp. 74-79, 2013.

[4] A.A. Khanova and A.S. Ponomareva, "Organization of decision-making in the form of the management cycle of organization efficiency," Vestnik Astrakhanskogo Gosudarstvennogo Technicheskogo Universiteta. Series:Upravlenie, vyichislitelnaya tehnika i informatika, no. 2, pp. 171-177, 2011.

[5] A.Yu. Filippovich, "Integration and convergence of modeling systems. The concept of SIE modeling," in Proc. School of sciences for young scientists "Computer graphics and mathematical modeling (Visual Computing)", Moscow, 2009, pp. 195-203.

[6] A. Yu. Filippovich, "The integrated SIE modeling," in Proc.XVII Nat. Russian scientific and methodical Conf. "Telematics'2010", St. Petersburg, 2010 , pp. 324 - 327.

[7] A. Tolk, Ontology, Epistemology, and Teleology for Modeling and Simulation. Springer, 2013.

[8] N.P. Ganyukova and A.A. Khanova, "Process management of systems of corporate type," Vestnik Saratovskogo gosudarstvennogo tehnicheskogo universiteta, vol. 3, no. 1(57), pp. 235-241, 2011. 
[9] O.M. Protalinsky, A.A. Khanova and I.O.Bondareva, "Imitating model of technological processes of cargo port," Vestnik Saratovskogo gosudarstvennogo tehnicheskogo universiteta, vol. 2, no. 4(50), pp.134$144,2011$.

[10] A.A. Khanova, N.S. Urazaliev and Z.A. Usmanova, "The method of situational control of complex systems based on the balanced scorecard parameters," Nauchnyiy vestnik Novosibirskogo gosudarstvennogo tehnicheskogo universiteta, no. 3(60), pp.69-82, 2015.

[11] O. V. Zamyatina, "Metod of modeling and complex analysis of business processes," Izvestiya Tomskogo politehnicheskogo universiteta, vol. 308, no. 6, pp.180-186, 2005.

[12] N. N. Mukhacheva and D. V. Popov, "Ontologic models and methods for management of information and intellectual resources of the organization," Vestnik Ufimskogo gosudarstvennogo aviatsionnogo tehnicheskogo universiteta, vol. 14, no. 1, pp. 123-135, 2010.

[13] Q. Li and H. S. L. Fan, "Simulation Model for Detecting Vessel Conflicts Within a Seaport," Int. J. on Marine Navigation and Safety of Sea Transportation, vol. 6, no. 1, pp. 11-17, Mar. 2012.

[14] A.A. Khanova, "Conceptual structure of the business management system on the basis of the integrated models (on the example of cargo port)," Nauchnotehnicheskie vedomosti Sankt-Peterburgskogo gosudarstvennogo politehnicheskogo universiteta. Seriya: Informatika. Telekommunikatsii. Upravlenie, no. 3(150), pp. 99-105, 2012.

[15] I.A. Shcherbatov and I.O. Protalinskiy, "Mathematical Modeling of Complex Multicomponent Systems," Vestnik Tambovskogo gosudarstvennogo tehnicheskogo universiteta, vol. 20, no. 1, pp. 17$26,2014$. 